\title{
CONF-961202--69
}

\section{YIELD STRESS ANOMALY IN B2 FeAl}

\author{
K. YOSHIMI*, S. HANADA* and M. H. YOO** \\ *Institute for Materials Research, Tohoku University, Sendai 980-77, Japan \\ **Metals and Ceramics Division, ORNL, Oak Ridge, TN 37831-6115, USA
}

\section{ABSTRACT}

Our studies on yield stress anomaly of B2 FeAl single crystals are reviewed in this paper. A positive temperature dependence of yield stress, so-called "yield stress anomaly", is observed in B2 FeAl in which excess vacancies are fully annealed out. Associated with the anomaly, characteristic asymmetry is found between tension and compression. While the strain-rate sensitivity is almost zero in the temperature range of the yield stress anomaly, the stress relaxation becomes significant with increasing temperature, indicating that a recovery process is thermally activated. It is ascertained by the two-surface trace analysis that slip transition from $\langle 111\rangle$ direction at intermediate temperature to $\langle 100\rangle$ at high temperature occurs around the peak temperature. Even at the peak temperature, in addition, operative slip vector for yielding is confirmed to be predominantly $<111>$ by TEM. Also, it is observed that $<111>$-type superdislocations are frequently climb-dissociated in the temperature range of the anomaly. APB formation on \{111\} plane is energetically favorable, which is in agreement with the Flinn's calculation for the B2 superlattice that APB energy on [111] plane is lower than that on [110] plane. Such an anisotropy of APB energy would offer specific driving force for the climb dissociation on $\langle 111\rangle$ superdislocations. On the basis of the observed results, the anomalous strengthening behavior of B2 FeAl single crystals is discussed.

\section{INTRODUCTION}

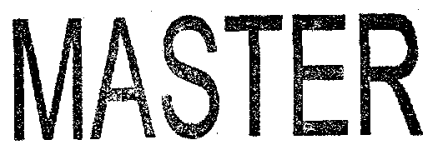

A mild peak of temperature-dependent yield stress in $\mathrm{B} 2 \mathrm{FeAl}$ was first observed in the paper by Baker and Gaydosh [1] who dealt with Fe-37Al-2Ni. (Compositions are described in mole per cent throughout this paper.) Later, Guo, Sun, Tan, Li and Lai [2] found the anomalous peak around $773 \mathrm{~K}$ in polycrystalline $\mathrm{Fe}-40 \mathrm{Al}+\mathrm{B}$. Chang [3] also found a distinct peak in largegrained, directionally solidified Fe-40Al. After Guo et al. [2] and Chang [3], the unusual yield behavior has become one of the hottest topics in B2 FeAl. Recently, the yield stress peak has been reported by many research groups [4 - 8], and also some theoretical and experimental efforts have been devoted to understanding the anomalous phenomenon in B2 FeAl [9-15]. Because of difficulty in assessing the prominent dislocation microstructure, a physical source(s) has not been identified. Though $\mathrm{\beta}-\mathrm{CuZn}$ and $\mathrm{DO}_{3} \mathrm{Fe}_{3} \mathrm{Al}$ are well-known to exhibit the yield stress anomaly [16 - 21], the anomalous strengthening mechanism has not been established for these either. Therefore, basic understanding of yielding and deformation behavior in $\mathrm{B} 2 \mathrm{FeAl}$ is not only necessary for clarifying the physical source(s) of the yield stress anomaly in B2 FeAl, but also very significant for a general viewpoint of the yield stress anomaly in bcc-base intermetallic compounds, including $\beta-\mathrm{CuZn}$ and $\mathrm{DO}_{3} \mathrm{Fe}_{3} \mathrm{Al}$.

In the present paper, we review the yield stress anomaly of $\mathrm{B} 2 \mathrm{FeAl}$, mainly our studies using single crystals. The observed yield stress anomaly of $\mathrm{B} 2 \mathrm{FeAl}$ will be discussed by comparing with those in $\beta-\mathrm{CuZn}$ and $\mathrm{DO}_{3} \mathrm{Fe}_{3} \mathrm{Al}$.

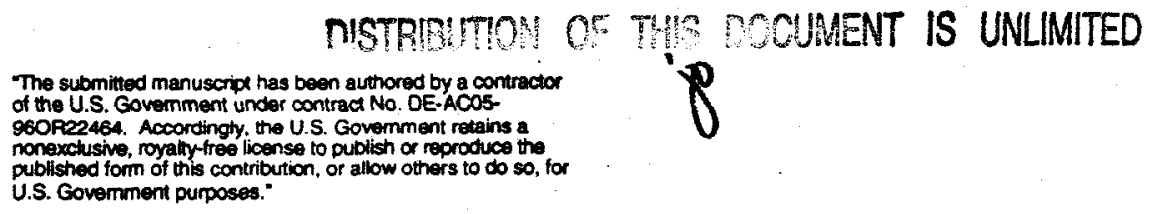




\section{DISCLAMMER}

Portions of this document may be illegible in electronic image products. Images are produced from the best available original document. 


\section{MACROSCOPIC STRENGTH AND DEFORMATION FEATURE OF SINGLE CRYSTALS}

\section{Temperature-dependent phenomena}

In single crystals, yield stress peaks can be observed clearly (Fig. 1). The onset temperatures $\left(T_{1}\right)$ observed in our studies, where yield stress begins to increase with increasing temperature, lie between $0.37 T_{\mathrm{c}}$ $\left(0.35 T_{\mathrm{m}}\right)$ and $0.44 T_{\mathrm{c}}\left(0.41 T_{\mathrm{m}}\right)$, and the peak temperatures $\left(T_{\mathrm{p}}\right)$ lie between $0.51 T_{\mathrm{c}}(0.47$ $\left.T_{\mathrm{m}}\right)$ and $0.59 T_{\mathrm{c}}\left(0.55 T_{\mathrm{m}}\right)$ near $40 \mathrm{Al}[11,12]$, where $T_{c}$ is the B2/A2 transformation temperature and $T_{\mathrm{m}}$ the melting point from the phase diagram [22]. In stress-strain curves (Fig. 2), work hardening rate gradually decreases with increasing temperature up to $T_{\mathrm{p}}$. Also, for some orientations, serrations appear above room temperature. Around $T_{p}$, serrations disappear over the whole strain range and instead a large yield drop takes place for all the orientations examined.

Figure 3 shows stress-strain curves of single crystals under higher magnification, which were obtained during the stress relaxation tests in compression. Below $T_{\mathrm{p}}$ (Fig. 3(a)), the stress amplitude of serrations increases with increasing temperature. Similar results had been already observed in polycrystalline $\mathrm{Fe}-43 \mathrm{Al}$ by Morris et al. [23]. The increment in flow stress after the stress relaxation is almost zero below $T_{p}$; i.e., static strain aging (SSA) in this temperature range $\left(<T_{p}\right)$ is not detectable in the crystal. Therefore, the serrations may not be due to dynamic strain aging (DSA) by solute atom atmospheres. At and just above $T_{\mathrm{p}}(823 \mathrm{~K}$ or 873 $\mathrm{K}$ ), single crystals exhibit a minimum of flow stress $\left(\sigma_{\mathrm{m}}\right)$ after yield drops with no serration (Fig. 3(b)). Slight increases in stress after the stress relaxation can be also noted. Stress gap, $\Delta \sigma_{y}$, between the peak stress after yielding, $\sigma_{p}$, and $\sigma_{m}$ is much larger than the stress increments after
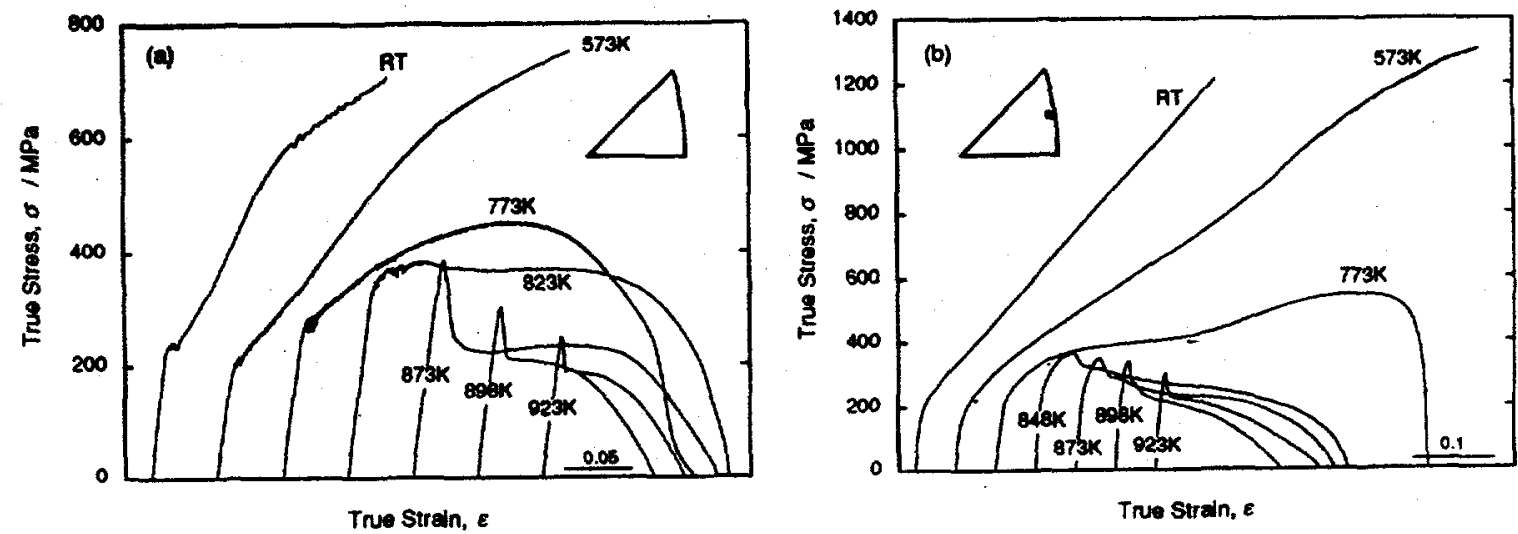

Fig. 2. Stress-strain curves of Fe-39Al single crystals obtained by tensile tests [12]. 

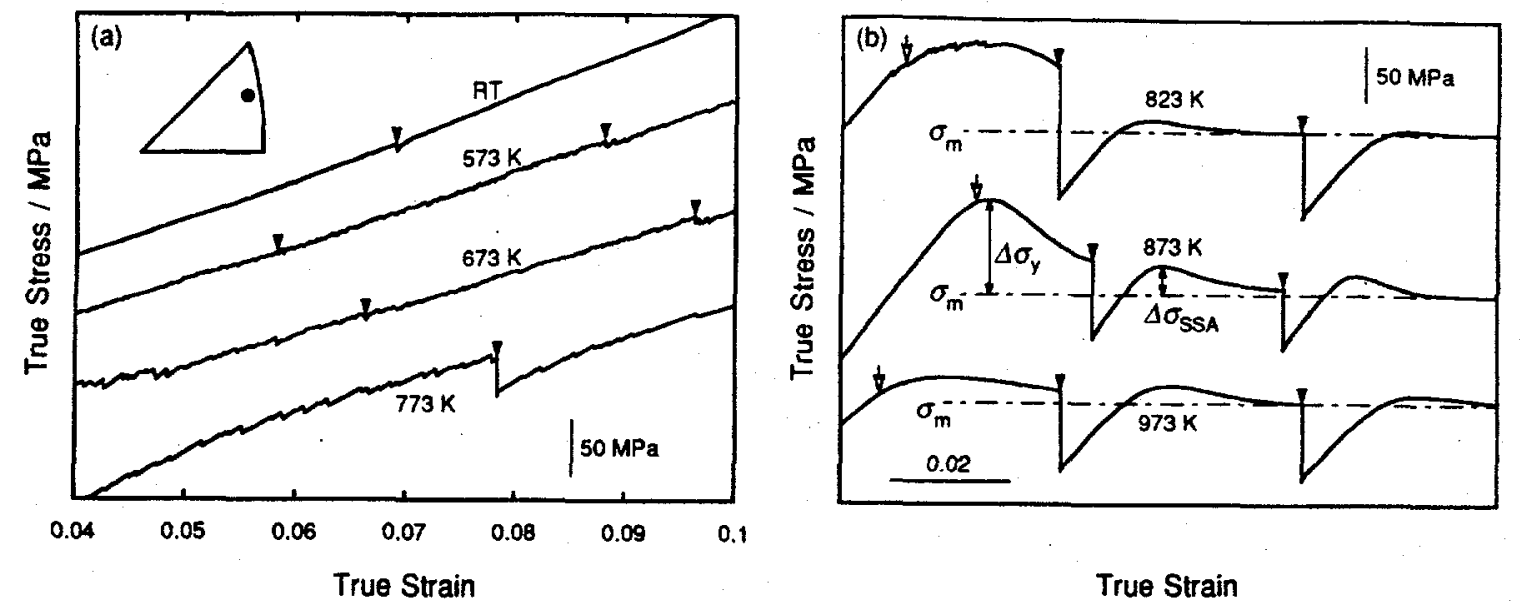

Fig. 3. Stress-strain curves of Fe-39.5Al single crystals obtained during the stress relaxation tests.

Filled arrows indicate the stress relaxation points and open arrows the $0.2 \%$ proof stress.

$\dot{\varepsilon}=1.6 \times 10^{-4} \mathrm{~s}^{-1}$. The relaxation time is $300 \mathrm{~s}$. (a) $\mathrm{T}<\mathrm{Tp}$. (b) $\mathrm{T} \geq \mathrm{Tp}$. Load ax is is shown in (a).

relaxing, $\Delta \sigma_{\mathrm{SSA}}$, at the temperatures. Since slip vector changes abruptly from the [111] direction to $<100>$ directions after yielding at $T_{\mathrm{p}}$ (see a later section), such a large $\Delta \sigma_{\mathrm{y}}$ may be attributed to the nucleation and multiplication of $<100\rangle$-type dislocations. At higher strain or temperature, the increase in stress after relaxing would be due to SSA associated with slip in $\langle 100\rangle$ directions, since the dominant operative slip direction is $\langle 100\rangle$.

Single crystals are relatively ductile [12]. We can obtain an elongation of about $17 \%$ in vacuum at room temperature even for the near $-<100>$ orientation. We can also obtain maximum elongation of more than $90 \%$ at an intermediate temperature, depending on load axes. Although the elongation steadily decreases with increasing temperature beyond the maximum, the decrease in the elongation does not result from a decline in ductility, but from a local necking due to nonuniform deformation.

\section{Orientation-dependent phenomena, and tension / compression ( $T / C)$ asymmetry}

In the temperature range of the yield stress anomaly of $\mathrm{B} 2 \mathrm{FeAl}$, yield stress or critical resolved shear stress (CRSS), and peak stress exhibit a characteristic orientation dependence.
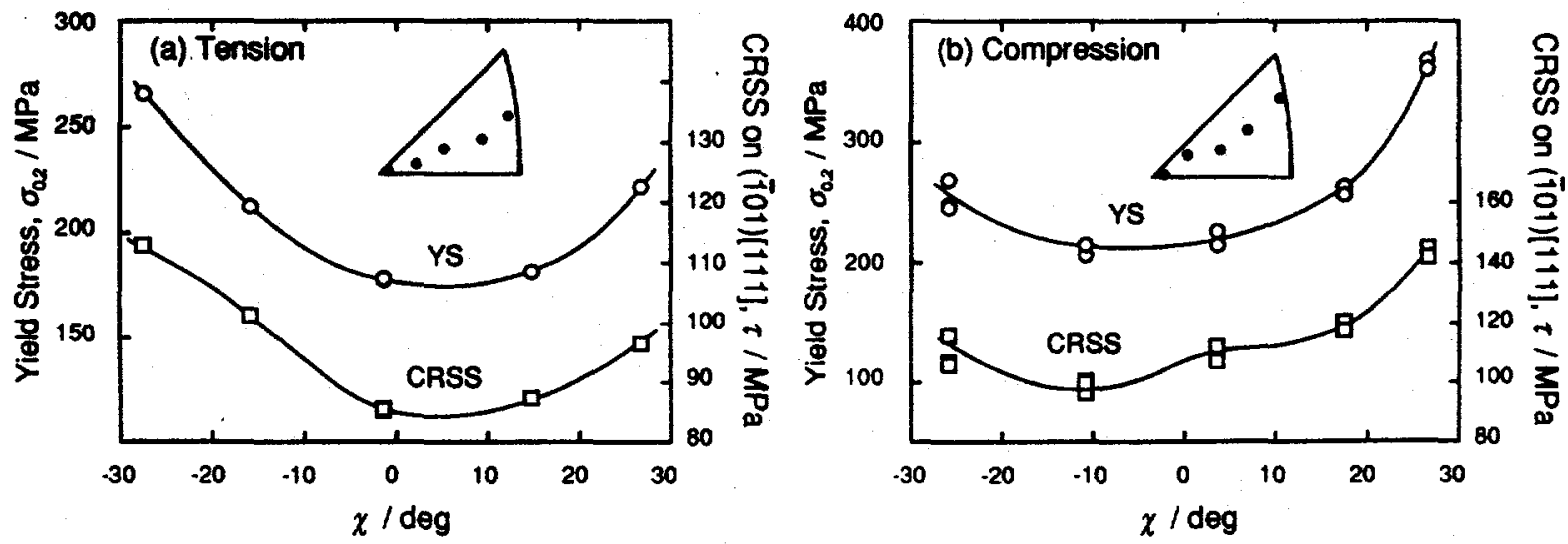

Fig. 4. $\chi$-dependence of yield stress and critical resolved shear stress of Fe-Al single crystals at $773 \mathrm{~K}$.

(a) $\mathrm{Fe}-39 \mathrm{Al}$ in tension [12]. (b) $\mathrm{Fe}-39.5 \mathrm{Al}$ in compression [11]. 


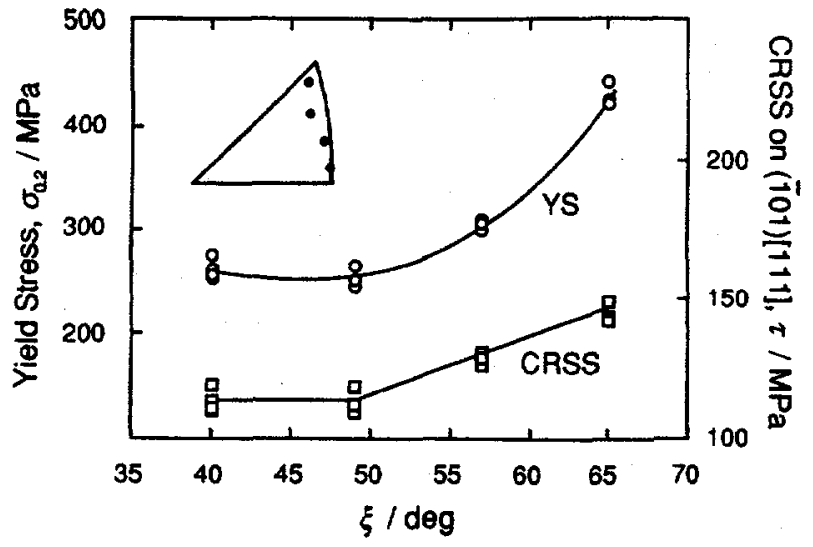

Fig. 5. $\xi$-dependence of yield stress and critical resolved shear stress of $\mathrm{Fe}-39.5 \mathrm{Al}$ single crystals at $773 \mathrm{~K}$ in compression [11].
Figure 4 shows orientation dependences of yield stress and CRSS at $773 \mathrm{~K}$ as a function of $\chi$, where $\chi$ is the angle between the direction normal to ( $\overline{1} 01$ ) primary slip plane and that to the maximum resolved shear stress (MRSS) plane (see Ref. [11]). It should be noted that the shape of the $\chi$ dependence is almost symmetrical between tensile and compressive straining mode, e.g., Fig. 4(a) and (b). In other words, we can express the $\chi$-dependence in general as that yield stress and CRSS exhibit a maximum near the twinning direction and increase again near the anti-twinning direction. This tension-compression $(T / C)$ symmetry of the $\chi$-dependence should be a part of the intrinsic nature of deformation behavior responsible for the yield stress anomaly. This $\chi$-dependence, however, is apparently different from that in $\beta$-CuZn obtained by Umakoshi et al. [17]. Furthermore, the yield stress and CRSS depend on $\xi$ (Fig. 5), where $\xi$ is the angle between the [111] direction and the load axes (also see Ref. [11]). This $\xi$-dependence is not in agreement with that predicted by the cross slip pinning (CSP) model.

The serrated flow behavior is also an orientation-dependent phenomenon. In tension case (Fig. 2), stress amplitude in serration is prominent for $\chi \leq 0^{\circ}$, and it becomes weak or disappears with increasing $\chi$. By contrast, in compression case, serrations were observed for the orientation of $\chi \geq 0^{\circ}$, while no serration for $\chi<0^{\circ}[11]$. Therefore, there exists a T/C symmetry also in the serrated flow behavior.

\section{Strain-rate-dependent phenomena}

Strain-rate sensitivity of yield stress of $\mathrm{B} 2 \mathrm{FeAl}$ single crystals is small at the strain rates examined in the temperature range of the yield stress anomaly, as shown in Fig. 6 [11]. The peak temperatures are also not so sensitive to the strain rates, but the peak stresses are remarkably sensitive. Nagpal and Baker [24] investigated the effect of strain rate on yield stress of Fe-45Al polycrystals at room temperature, and found that yield stress hardly changed with the strain rate under $10^{-2} \mathrm{~s}^{-1}$. These results indicate that yield stress is hardly sensitive to strain rate in a relatively wide temperature range below $T_{\mathrm{p}}$.

Very small strain-rate sensitivity of flow stress was confirmed by the strain-rate change tests [11]. On the other hand, in the temperature range of the yield stress anomaly, the strain-rate dependence of work hardening rate increases with increasing temperature. The work hardening rate becomes higher at a higher strain rate, indicating a normal, positive strain-rate dependence. This result on the strain-rate dependence of work hardening rate suggests that the recovery process is thermally activated in the temperature range.

The strain-rate sensitivity and the relaxation stress are plotted together as functions of temperature in Fig. 7. Within the accuracy of the recording system, $I$ ( $\equiv d \sigma / d \ln \dot{\varepsilon}$ ) is essentially zero up to $T_{\mathrm{p}}$, as mentioned above. At $T_{\mathrm{p}}$, it increases drastically and reaches a maximum. Above $T_{\mathrm{p}}$, it exhibits a conspicuous value $(I \sim 35 \mathrm{MPa})$ in contrast with those $(I-0 \mathrm{MPa})$ below $T_{\mathrm{p}}$. The temperature dependence of the stress relaxation (solid curve in Fig. 7 ) shows a tendency 


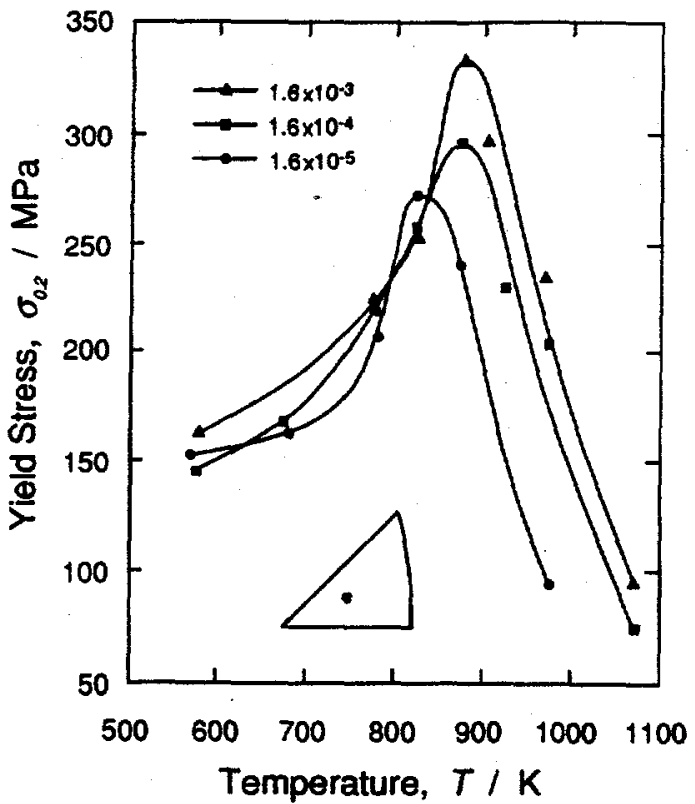

Fig. 6. Temperature dependence of yield stress of Fe-39.5Al single crystals for three strain rates [11].

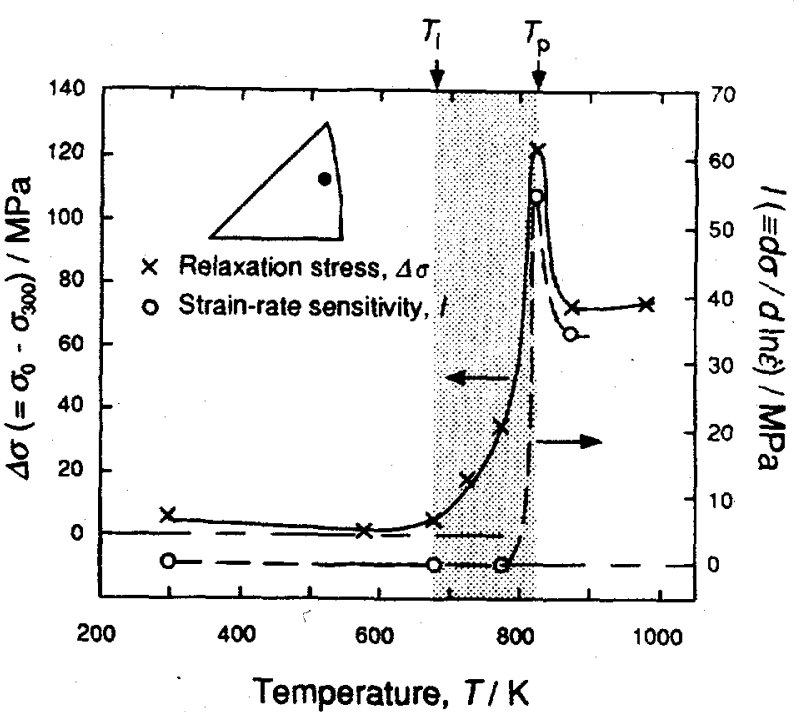

Fig. 7. Temperature dependence of the strain-rate sensitivity, $l$, and of the relaxation stress, $\Delta \sigma$. The strain-rate sensitivity was estimated by strain-rate changing from $1.6 \times 10^{-4} \mathrm{~s}^{-1}$ to $1.6 \times 10^{-3} \mathrm{~s}^{-1}$ at about $3 \%$ plastic strain after yielding. The relaxation stress was measured by the flow stress over $300 \mathrm{~s}$ at about $3 \%$ plastic strain, by stopping the cross head movement.

similar to that of the strain-rate sensitivity (dashed curve) apparently, but in the domain of the yield stress anomaly, the relaxation stress, $\Delta \sigma$, increases gradually with increasing temperature. When a recovery process takes place during the stress relaxation, the deviation from a logarithmic relaxation rate becomes large in the relaxation curve. On the other hand, a true relaxation rate ought to be as small as that below $T_{1}$ in the temperature range of the anomaly, since $I$ is almost zero. Therefore, the increase in $\Delta \sigma$ with temperature in the domain of the anomaly is attributed to an increase in a recovery rate. As the recovery process is diffusion-controlled, the rise in the recovery rate originates from enhancement in atomic diffusivity. Accordingly, we can expect that deformation above $T_{1}$ is controlled by a diffusion-assisted process of dislocation motion.

\section{SLIP TRANSITION AND DEFORMATION MICROSTRUCTURE}

Umakoshi and Yamaguchi first reported that slip direction changes from $<111>$ at lower temperature to $\langle 100\rangle$ at higher temperature $[25,26]$. A similar slip transition has been reported also in $\mathrm{Fe}_{3} \mathrm{Al}[27]$ and $\beta-\mathrm{CuZn}[28,29]$. In $\beta-\mathrm{CuZn}$, Saka and his colleagues observed that the fraction of densities of $<111>-$ type and non- $<111>$-type dislocations drastically changes around $T_{\mathrm{p}}[28,29]$. The reason why the yield stress anomaly was not observed in the reports by Umakoshi and Yamaguchi $[25,26]$ is probably due to the excess vacancy strengthening that might have obscured it $[6,14]$. Till recently, a relationship between the yield stress anomaly and the slip transition had not been well established in B2 FeAl.

Slip directions determined by the two-surface trace analysis are shown in Fig. 1. It should be noted that the macroscopic slip transition temperatures coincide with the peak temperatures. Accordingly, the decline in yield stress above $T_{\mathrm{p}}$, was attributed to a negative temperature dependence of CRSS for the slip in non- $<111>$ directions. 
As shown in Fig. 8, at $T_{\mathrm{p}}$, a deforming crystal exhibits serrated flow, and slip is very inhomogeneous within some initial strain (curves $a$ and $b$ ). As shown in the inserted photograph $a$ of Fig. 8, only a few coarse slip bands parallel to (101) plane appear on the surface of a specimen strained to a near-yield strain of $0.5 \%$. With increasing strain, the slip bands propagated over the specimen. Beyond the certain strain $(-2 \%)$, serrations disappear and instead remarkable work-softening occurs (curve $c$ ). A surface of the specimen corresponding to the curve $c$ is shown in the inserted photograph $c$. As slip bands propagated throughout the entire specimen, slip traces other than the ( $\overline{1} 01)$ planes were also detected on the surface. Thus, it can be expected that dislocation structures in the specimen $a, b$ and $c$ would be all very different.

Dislocation structure within a coarse slip band of the specimen $a$ is shown in Fig. 9 . Almost all the dislocations were confirmed to be of [111]-type by using conventional $\mathbf{g} \cdot \mathbf{b}=0$ invisibility criteria under several $\mathbf{g}$ vectors. Hence, it was revealed that $<111>$ slip is predominantly activated at the early stage of plastic deformation even at $T_{\mathrm{p}}$. This result also confirms that the yield stress anomaly is caused by the increase in the glide resistance to $<111>$-type superdislocations.

Figure 10 shows bright-field micrographs of dislocation structure of specimen $b$ in Fig. 8, which was strained before work-softening. Interestingly, most of the dislocations are out of contrast or in weak residual contrast under $g=020$ (Fig. 10(a)), while others exhibit a weak, dotted contrast under $g=101$ (Fig. $10(\mathrm{~b})$ ). These results of the contrast analysis indicate that those dislocations are of non-[111], i.e., $\langle 100\rangle$ or $\langle 110\rangle$-type. We deduce from this evidence

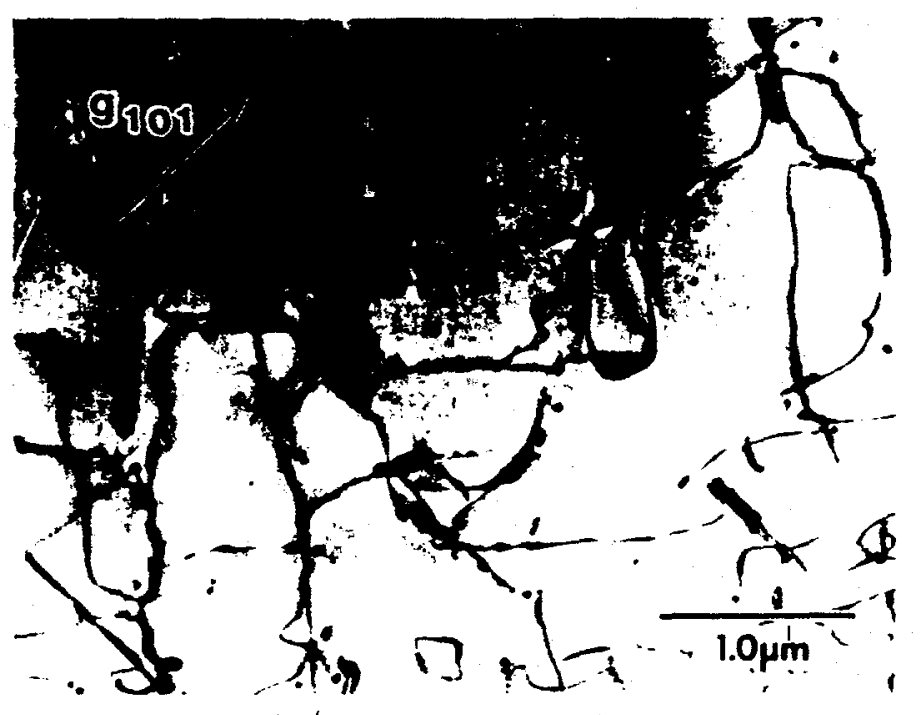

Fig. 9. Bright field micrograph taken in a slip band of specimen $a$. $B \cong$ [101]. $\mathrm{g}=101$. 


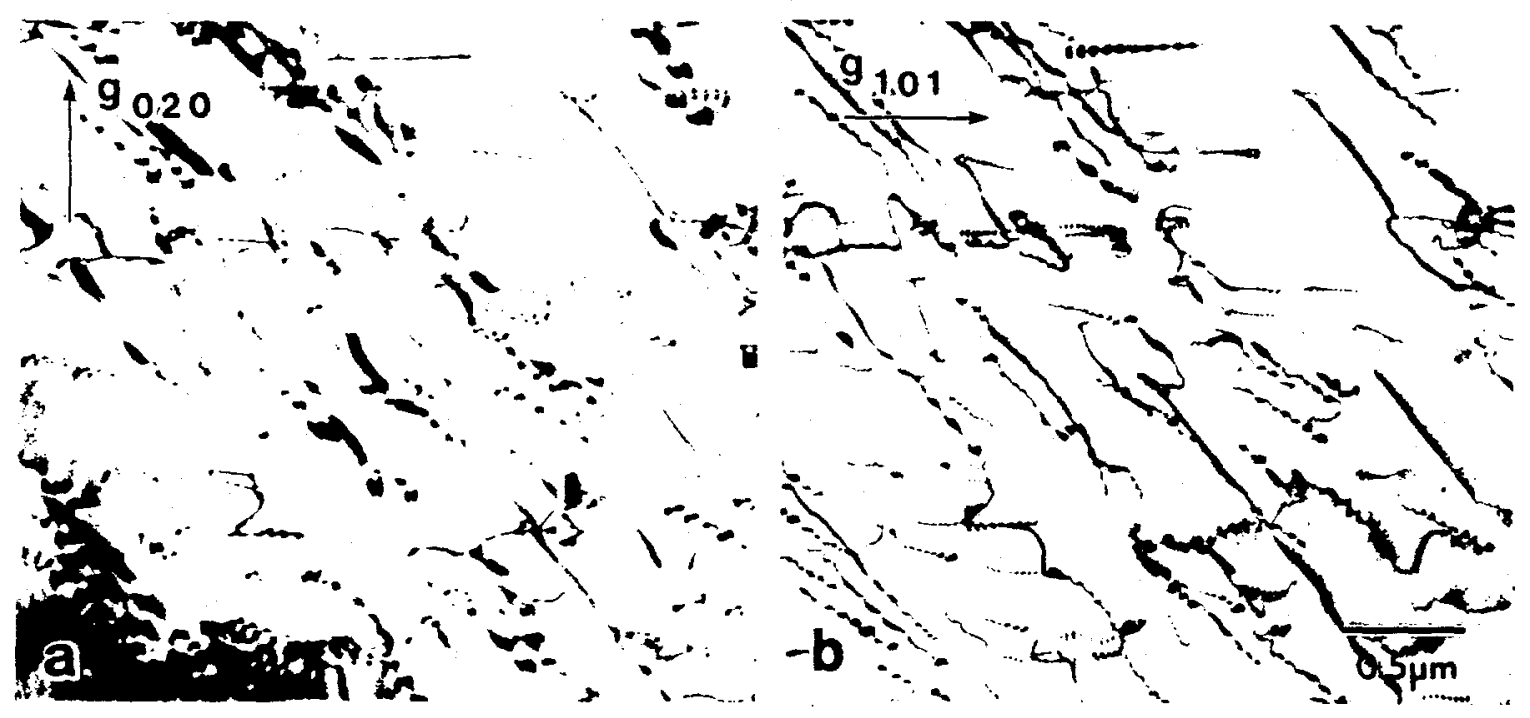

Fig. 10. Bright field micrographs taken in specimen $b$. $B \equiv[\overline{1} 01]$. (a) $g=020$. (b) $g=1.01$.
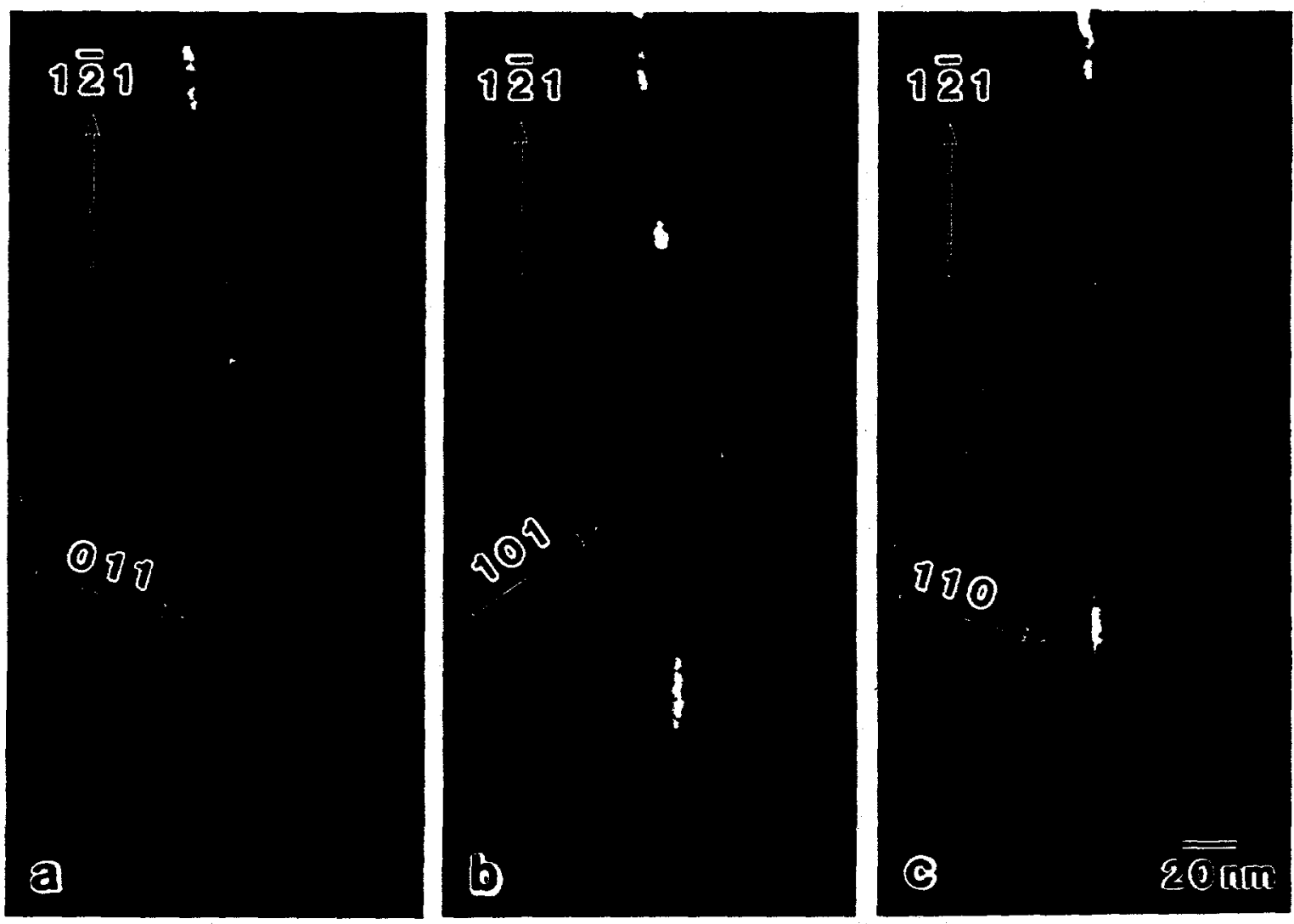

Fig. 11. Weak-beam micrographs upon tilting around the [1리 direction in the same foil as in Fig. 9 under $\mathbf{g}-4 \mathrm{~g}$ condition. (a) $\mathrm{B} \equiv[\overline{3} \overline{\mathrm{l}} \mathrm{l}] . \mathbf{g}=011$. (b) $\mathrm{B} \equiv[\overline{1} 01] . \mathbf{g}=101$. (c) $\mathrm{B} \equiv$ [113]. $\mathbf{g}=110$. 
that slip direction changes during deformation with increasing strain. In the specimen $c$, almost all dislocations were of $<100>$-type, suggesting that the slip transition had been already completed at this strain.

Figure 11 shows weak-beam micrographs taken by the tilting experiment using the [1 $\overline{2} 1]$ axis in the same foil as in Fig. 9. It can be seen that the near-edge segment is not dissociated into superpartials from the direction normal to the macroscopic slip plane, i.e., the (101) plane (Fig. 11 (b)). On the other hand, it is found to partly dissociate into superpartials from the [ $\overline{3} \overline{1} 1]$ and the $[\overline{1} 13]$ directions, which are apart by $30^{\circ}$ around the $[1 \overline{2} 1]$ axis. Those dislocation pairs are not dipoles, but consist of superpartials, indicating that those $<111>$-type superdislocations are climb-dissociated. Such a climb dissociation was often observed in the specimens deformed in the domain of the anomaly. From these observations, we conjecture that the climb dissociation may generate locking stress in the temperature range of the anomaly. However, we cannot observe the arrangement of <111>-type superdislocations preferentially along a specific orientation, such as edge or screw direction at the peak temperature (Fig. 9), which is different from the microstructure observed in some $\mathrm{Ll}_{2}$ intermetallic compounds [e.g. 30 - 33]. These "feature-less" deformation microstructures of mixed dislocation characters in the domain of the yield stress anomaly prevent us from ascertaining the pinning mechanisms for $<111>$-type superdislocations.

\section{DISCUSSION}

The results shown in Figs. 8 and 9 confirm that yield stress anomaly of B2 FeAl is induced by the increase in the glide resistance to $<111>$-type superdislocations with increasing temperature. In our early work [10], we observed the decomposed configuration of [111]-type dislocations into [010]-type and [101]-type ones in the specimen deformed just below $T_{\mathrm{p}}$. However, decomposition was hardly observed in the specimen deformed at $T_{\mathrm{p}}$ in spite of a still significant $<111>$ slip activity (Fig. 9). This means that such decomposition is not a major cause for the yield stress anomaly.

As shown in Figs. 8 - 10, it was found that the slip direction changed from $\langle 111\rangle$ to $<100>$ during deformation with increasing strain at $T_{\mathrm{p}}$. This suggests that the decomposition may still occur during work hardening and it may become the primary source for $<100>$-type dislocations. Indeed, the density of $\langle 111\rangle$-type dislocations is much lower after the transition (Fig. 10) than before it (Fig. 9). If the source of $<100>$-type dislocations was activated independently from decomposition, there would be more $<111>$-type dislocations left in the specimen.

Since the yield stress above $T_{\mathrm{p}}$ is controlled by CRSS of $\langle 100\rangle$ slip, $T_{\mathrm{p}}$ is determined as the intersection between the yield stress curves for the $\langle 111\rangle$ slip and that for the $\langle 100\rangle$ slip. Peak temperatures in the Fe-Al system reported by many researchers $[1-8,10-15,20,21,27$, 33 - 36] are summarized in Fig. 12. At the aluminum content less than about $30 \%$, where alloys are undoubtedly of the $\mathrm{DO}_{3}$-ordered state at room temperature, the data of the peak temperatures are located around $800 \mathrm{~K}$ with a small scatter. On the other hand, at aluminum contents greater than $30 \%$, the observed peak temperatures are much more scattered. As one of possible causes for the good reproducibility of the peak temperatures at lower aluminum contents, we can recognize the role of the first-order phase transformation $\left(\mathrm{DO}_{3} /\left(\mathrm{DO}_{3}+\alpha\right)\right)$ and the second-order one $\left(\mathrm{DO}_{3} / \mathrm{B} 2\right)$. Some results indicate that peak temperatures lie above the transformation temperatures $[21,35]$. This evidence suggests that the phase transformations are not a direct 


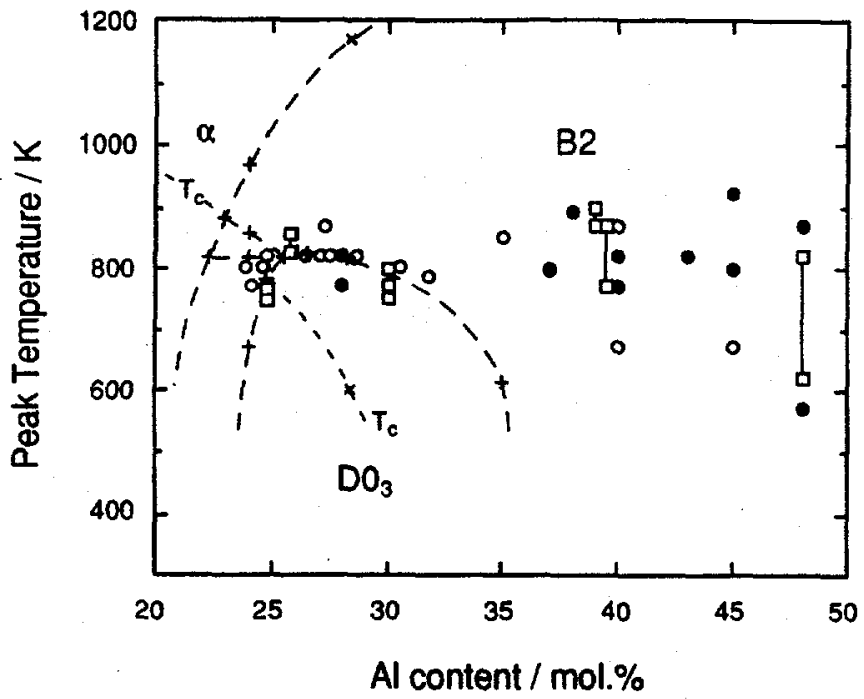

Fig. 12 Peak temperature reported in Refs. $[1-8,10-15,20,21,27,33-36]$ as a function of Al content. Open circles indicate binary polycrystals, filled ones polycrystals modified by added elements, and open squares binary single crystals. Broken lines indicate the phase transformation temperature reported in Refs $[22,53]$.

source for the increase in yield stress. Furthermore, the peak temperatures do not correspond to the transformation temperatures at higher aluminum contents. Thus, it is reasonable to seek a common strengthening mechanism other than the phase transformations operating on $\langle 111\rangle$-type superdislocations in the wide composition range irrespective of ordered states.

The local climb locking [9] is one of the most convincing locking mechanisms for the yield stress anomaly observed in B2 FeAl. According to Flinn's calculation [37], APB energies for B2-ordered structure are ranked as $\{001\}>\{112\}>\{110\}>\{111\}$. If this calculation is correct, it is expected that the climb-dissociated configuration is energetically preferable to the glide-dissociated one for $<111>$-type superdislocations, since the $\{111\}$ plane is the climb plane for the edge character. This energetic preference induced by the anisotropy of APB energy would offer specific driving force for the climb dissociation of edge dislocations. Thermal formation of APBs on $\{111\}$ planes (Fig. 13) has been reported in Fe-Al containing more than 35\% Al [38 41]. Yoshimi et al. [41] interpreted the APB formation as a result of collapse of the lattice owing to vacancy condensation on triple layers of $\{111\}$ planes during a heat treatment at an intermediate temperature. Such APB formation indicates that APB energy is estimated to be lower on the

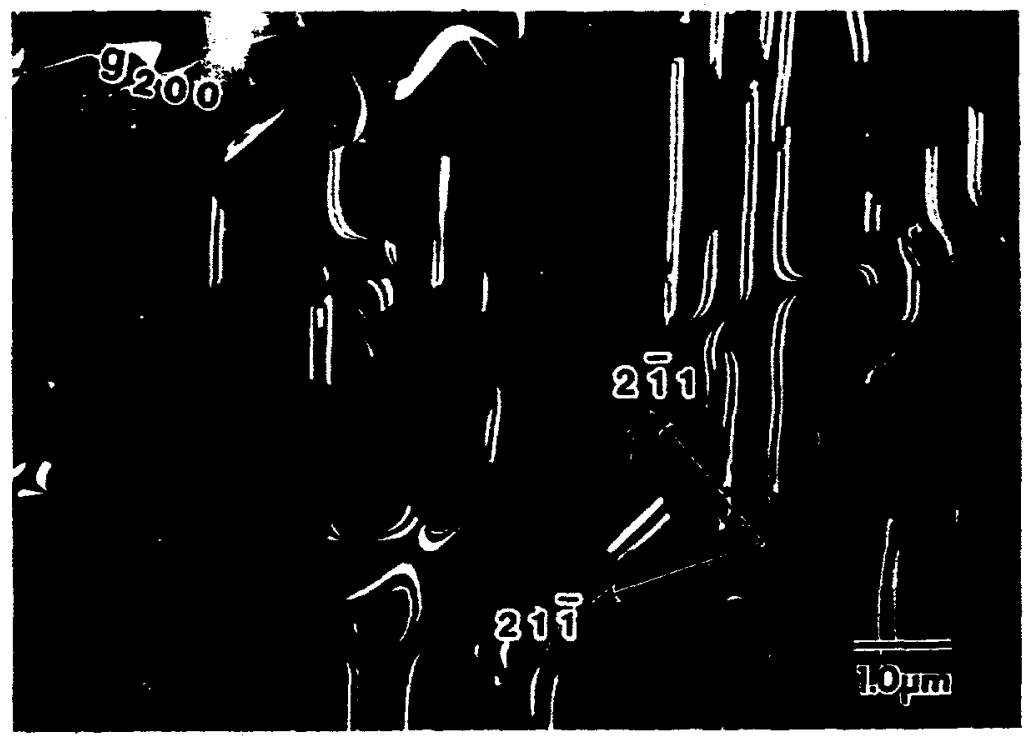

Fig. 13. A typical APB structure formed by vacancy condensation in Fe-35Al [41]. 
[111\} plane than on the $\{110\}$ plane even at the elevated temperature. This result strongly supports the result calculated by Flinn [37]. Moreover, Marcinkowski and Brown [42] calculated $\mathrm{NN}$ - and NNN-APB energies in $\mathrm{DO}_{3} \mathrm{Fe}_{3} \mathrm{Al}$ in the similar manner to Flinn's, where NN-APB is the APB introduced by $\frac{1}{4} \mathrm{a}_{0}{ }^{\prime}<111>$ shear displacement in the $\mathrm{DO}_{3}$ lattice, NNN-APB by $\frac{1}{2} \mathrm{a}_{0}{ }^{\prime}<111>$ or $\frac{1}{2} \mathrm{a}_{0}{ }^{\prime}<100>$ shear displacement, and $\mathrm{a}_{0}{ }^{\prime}$ the lattice parameter of $\mathrm{DO}_{3} \mathrm{Fe}_{3} \mathrm{Al}$. According to their calculation [42], the NN-APB energy exhibits the anisotropy similar to that in B2 compounds calculated by Flinn, while the NNN-APB energy exhibits the anisotropy opposite to NN-APB energy and that in $\mathrm{B} 2$ compounds. The anisotropy of the APB energies in $\mathrm{D0}_{3} \mathrm{Fe}_{3} \mathrm{Al}$ has been also supported by the observation by Mendiratta et al. [43]. Thus, it can be expected that specific driving force for climb dissociation also exists between superpartials connected by $\mathrm{NN}-\mathrm{APB}$ in $\mathrm{Fe}_{3} \mathrm{Al}$. This interpretation is in good agreement with a TEM result observed by Morris et al. [27]. In addition, it is worth noting that the superpartial pairs connected by NNAPB are equivalent to superpartial pairs in B2 FeAl. Consequently, we can consider that the driving force for the climb dissociation results from the same origin for both $\mathrm{DO}_{3} \mathrm{Fe}_{3} \mathrm{Al}$ and $\mathrm{B} 2$ FeAl. Climb-dissociation of superdislocations in B2 compounds has been investigated for the yield stress anomaly in $\beta$-CuZn by Saka and Zhu [44], Zhu and Saka [45] and Dirras et al. [46]. However, Dirras et al. [46] denied that the anomaly results only from the climb dissociation.

Frictional stress due to APB dragging would be another that may give rise to the glide resistance on <111>-type superdislocations. In Brown's original idea [47], the frictional stress is proportional to temperature and square of long range order parameter, and inverse to Burgers vector. Applying this concept to $\mathrm{B} 2 \mathrm{FeAl}$ having the composition more than $35 \% \mathrm{Al}$ as an example, the frictional stress must increase with increasing $\mathrm{Al}$ content at an elevated temperature. Because the fraction of $\mathrm{Al}$-sites occupied by $\mathrm{Fe}$ atoms decreases, i.e., the long range order state rises with increasing $\mathrm{Al}$ content [ 48 - 50], which is hardly reduced up to a high temperature above $T_{\mathrm{p}}$ [22], although the lattice parameter is almost constant in this composition range [51]. We have, unfortunately, no available data for this discussion at present, because yield stress in the domain of the anomaly is drastically changed by impurity level, crystal orientation, heat treatment, microstructure, and so on, as shown in Fig. 12. Beauchamp et al. [52] investigated the structure of the APB on $\{110\}$ plane in $\beta-C u Z n$ using CVM and attempted to explain yield stress anomaly of $\beta-\mathrm{CuZn}$ on the basis of APB dragging mechanism. The barrier against dislocation motion adopted in their model is the atomic rearrangement at APB. They pointed out that the strengthening caused by both APB rearrangement and the climb dissociation belongs to the same family of phenomena. Although their prediction for $T_{1}$ and $T_{\mathrm{p}}$ is apparently in agreement with our results observed in FeAl single crystals, it still leaves us with difficulty to expand their model over Fe-Al system.

\section{SUMMARY}

In our study by using B2 FeAl single crystals, it was confirmed that $<111\rangle$ slip is activated predominantly at the early stage of plastic deformation even at $T_{\mathrm{p}}$. This observation indicates that the yield stress anomaly is caused by the increase in the glide resistance against $<111>$-type superdislocations. Also, it has been revealed that the temperature domain of the anomaly is that a thermally-activated recovery process is gradually enhanced with increasing temperature out of the regime of low temperature deformation mode with no diffusional assist. In addition, work hardening exhibits a normal, positive strain rate sensitivity in the temperature range. Accordingly, we can expect that deformation in the temperature domain of the anomaly is controlled by a 
diffusion-assisted process of dislocation motion such as climb dissociation and/or APB dragging. The APB formation on $\{111\}$ plane by vacancy condensation indicates that APB energy on $\{111\}$ plane is lower than that on $\{110\}$ plane. This anisotropy of APB energy would generate energetically stable core configuration for climb dissociated edge dislocations. However, we could not observe the arrangement of $<111\rangle$-type superdislocations preferentially along the edge orientation in the domain of the anomaly. These feature less dislocation microstructures are the ones keeping us from conclusively determining the pinning sites on $<111>$-type dislocations.

We still leave several unsolved problems for understanding the yield stress anomaly of B2

FeAl. For examples, very small strain rate sensitivity, orientation dependence and $\mathrm{T} / \mathrm{C}$ asymmetry of yield stress and serration flow, effect of work hardening at micro strains, and so on. In order to solve the above problems, further basic researches by means of precise experiments using single crystals are needed.

\section{ACKNOWLEDGMENT}

This research was sponsored by Grant-in-Aid for Scientific Research on Priority Area from the Ministry of Education, Science and Culture, Japan, and by the Division of Materials Sciences, U. S. Department of Energy under contact number DE-AC05-96OR22464 with Lockheed Martin Energy Research Corporation.

\section{REFERENCE}

1. I. Baker and D. J. Gaydosh, Mater. Sci. Eng., 96, 147 (1987).

2. J. T. Guo, C. Sun, M. H. Tan, H. Li and W. H. Lai, Acta Metall.Sinica A, 3, 249 (1990).

3. $\quad$ K. -M. Chang, Metall. Trans. A, 21A, 3027 (1990).

4. H. Xiao and I. Baker, Scripta Metall. Mater., 28, 1411 (1993).

5. J. T. Guo, O. Jin, W. M. Yin and T. M. Wang, Scripta Metall. Mater., 29, 783 (1993).

6. K. Yoshimi, S. Hanada and H. Tokuno, Mater. Trans. JIM, 35, 51 (1994).

7. O. Klein and I. Baker, Scripta Metall. Mater., 30, 1413 (1994).

8. T. Onuma, M. S. Thesis, (Tohoku University, 1995).

9. D. G. Morris, Phil. Mag. A, 71, 1281 (1995).

10. K. Yoshimi and S. Hanada, in Structural Intermetallics, ed. by R. Darolia, J. J. Lewandowski, C. T. Liu, P. L. Martin, D. B. Miracle and M. V. Nathal, (TMS, Warrendale, PA, 1993), p. 475.

11. K. Yoshimi, S. Hanada and M. H. Yoo, Acta Metall. Mater., 43, 4141 (1995).

12. K. Yoshimi, S. Hanada and M. H. Yoo, Intermetallics, 4, 159 (1996).

13. N. Matsumoto, M. S. Thesis, (Tohoku University, 1994).

14. R. Carleton, E. P. George and R. H. Zee, Intermetallics, 3, 433 (1995).

15. K. Yoshimi, S. Hanada and M. H. Yoo, Intermetallics, 4, S159 (1996).

16. G. W. Ardley and A. H. Cottrell, Proc. Roy. Soc., 219, 328 (1953).

17. Y. Umakoshi, M. Yamaguchi, Y. Namba and K. Murakami, Acta Metall., 24, 89 (1976).

18. A. Nohara, M. Izumi, H. Saka and T. Imura, Phys. Stat. Sol. (a), 82, 163 (1984).

19. A. Lawley, E. A. Vidoz and R. W. Cahn, Acta Metall., 9, 287 (1961).

20. N. S. Stoloff and R. G. Davies, Acta Metall., 12, 473 (1964).

21. S. Hanada, S. Watanabe, T. Sato and O. Izumi, Scripta Metall., 15, 1345 (1981).

22. G. Inden and W. Pepperhoff, Z. Metallkde., 81, 770 (1990).

23. D. G. Morris, J. C. Joye and M. Leboeuf, Phil. Mag. A, 69, 961 (1994).

24. P. Nagpal and I. Baker, Scripta Metall. Mater., 25, 2577 (1991).

25. Y. Umakoshi and M. Yamaguchi, Phil. Mag. A, 41, 573 (1980). 
26. Y. Umakoshi and M. Yamaguchi, Phil. Mag. A, 44, 711 (1981).

27. D. G. Morris, D. Peguiron and M. Nazmy, Phil. Mag. A, 71, 441 (1995).

28. H. Saka and M. Kawase, Phil. Mag. A, 49, 525 (1984).

29. A. Matsumoto and H. Saka, Phil. Mag. A, 67, 217 (1993).

30. B. H. Kear and H. G. F. Wilsdorf, Trans. TMS-AIME, 224, 382 (1962).

31. P. H. Thornton, R. G. Davies and T. L. Johnston, Metall. Trans., 1, 207 (1970).

32. S. Takeuchi and E. Kuramoto, Acta Metall., 21, 415 (1973).

33. P. Morgand, P. Mouturat and G. Sainfort, Acta Metall., 16, 867 (1968).

34. W. Schröer, H. Mecking and Ch. Hartig, in Intermetallic Compounds, ed. by O. Izumi, (JIM, Sendai, Japan, 1991), p. 567.

35. J. W. Park, I. G. Moon and J. Yu, J. Mater. Sci, 26, 3062 (1991).

36. H. Rösner, G. Molenat, M. Kolbe and E. Nembach, Mater. Sci. Eng., A192/193, 793 (1995).

37. P. A. Flinn, Trans. TMS-AIME, 218, 145 (1960).

38. D. Weber, M. Meurtin, D. Paris, A. Fourdeux and P. Lesbats, J. Phys. C7, 38, 332 (1977).

39. N. Junqua, J. C. Desoyer and P. Moine, Phys. Stat. Sol. (a), 18, 387 (1973).

40. A. Fourdeux and P. Lesbats, Phil. Mag. A, 45, 81 (1982).

41. K. Yoshimi, S. Hanada, T. Onuma and M. H. Yoo, Phil. Mag. A, 73, 443 (1996).

42. M. J. Marcinkowski and N. Brown, J. Appl. Phys., 33, 537 (1962).

43. M. G. Mendiratta, S. K. Ehlers and H. A. Lipsitt, Metall. Trans. A, 18A, 509 (1987).

44. H. Saka and Y. M. Zhu, Phil. Mag. A, 51, 629 (1985).

45. Y. M. Zhu and H. Saka, Phil. Mag. A, 59, 661 (1989).

46. G. Dirras, P. Beauchamp and P. Veyssiére, Phil. Mag. A, 65, 815 (1992).

47. N. Brown, Phil. Mag., 4, 693 (1959).

48. A. J. Bradley and A. H. Jay, Proc. Roy. Soc. A, 136, 210 (1932).

49. A. Lawley and R. W. Chan, J. Phys. Chem. Solids., 20, 204 (1961).

50. T. Eguchi, H. Matsuda, K. Oki, S. Kiyoto and K. Yasutake, Trans. JIM, 8, 174 (1967).

51. H. J. Leamy, E. D. Gibson and F. X. Kayser, Acta Metall., 15, 1827 (1967).

52. P. Beauchamp, G. Dirras and P. Veyssiére, Phil. Mag. A, 65, 477 (1992).

53. W. Köster and T. Gödecke, Z. Metallkde., 71, 765 (1980).

\section{DISCLAIMER}

This report was prepared as an account of work sponsored by an agency of the United States Government. Neither the United States Government nor any agency thereof, nor any of their employees, makes any warranty, express or implied, or assumes any legal liability or responsibility for the accuracy, completeness, or usefulness of any information, apparatus, product, or process disclosed, or represents that its use would not infringe privately owned rights. Reference herein to any specific commercial product; process, or service by trade name, trademark manufacturer, or otherwise does not necessarily constitute or imply its endorsement, recommendation, or favoring by the United States Government or any agency thereof. The views and opinions of authors expressed herein do not necessarily state or reflect those of the United States Government or any agency thereof. 